\title{
ORALIDISEASES
}

\section{HLA-C/KIR GENOTYPES IN ORAL LICHEN PLANUS PATIENTS INFECTED OR NON INFECTED WITH HEPATITIS C VIRUS}

\begin{tabular}{|r|l|}
\hline Journal: & Oral Diseases \\
\hline Manuscript ID: & ODI-04-10-OM-1620.R2 \\
\hline Manuscript Type: & Original Manuscript \\
\hline Duthe Submitted by the & 28-Jun-2010 \\
\hline Authote List of Authors: & $\begin{array}{l}\text { Carrozzo, Marco; University of Newcastle Upon Tyne, Oral Medicine } \\
\text { Elia, Alessandra; University of Turin, Division of } \\
\text { Otorhinolaryngology, Department of Clinical Physiopathology, Oral } \\
\text { Medicine Section } \\
\text { Mereu, Valentina; University of Turin, Departments of Genetics, } \\
\text { Biology and Biochemistry, } \\
\text { Dametto, Ennia; Molinette Hospital, , Transplantation Immunology } \\
\text { Service } \\
\text { Fasano, Maria; Molinette Hospital, , Transplantation Immunology } \\
\text { Service } \\
\text { Broccoletti, Roberto; University of Turin, Division of } \\
\text { Otorhinolaryngology, Department of Clinical Physiopathology, Oral } \\
\text { Medicine Section } \\
\text { Rendine, Sabina; University of Turin, Departments of Genetics, } \\
\text { Biology and Biochemistry, } \\
\text { Amoroso, Antonio; University of Turin, Departments of Genetics, } \\
\text { Biology and Biochemistry, }\end{array}$ \\
\hline \hline Immunology and Microbiology, Genetics, Medicine \\
\hline \hline
\end{tabular}

\section{今 scholaronE" \\ Manuscript Central}




\section{HLA-C/KIR GENOTYPES IN ORAL LICHEN PLANUS INFECTED OR NON INFECTED WITH HEPATITIS C VIRUS}

PATIENTS

Carrozzo $\mathrm{M}^{1}$, Elia $\mathrm{A}^{2,3}$, Mereu $\mathrm{V}^{4}$, Dametto ${ }^{4}$, Fasano $\mathrm{ME}^{4}$, Broccoletti $\mathrm{R}^{2,3}$, Rendine $\mathrm{S}^{4}$, Amoroso A ${ }^{4}$

${ }^{1}$ Department of Oral Medicine, School of Dental Sciences, Newcastle upon Tyne University, Newcastle upon Tyne, UK;

${ }^{2}$ Department of Biomedical Sciences and Human Oncology, Oral Medicine Section, University of Turin, Turin, Italy;

${ }^{3}$ Division of Otorhinolaryngology, Department of Clinical Physiopathology, Oral Medicine Section, University of Turin, Italy and

${ }^{4}$ Departments of Genetics, Biology and Biochemistry, Transplantation Immunology Service, San Giovanni Hospital of Turin, School of Medicine and Dentistry, University of Turin, Turin, Italy

Running Title: OLP and HLA-C/KIR genotypes

Key words: KIR; Hepatitis C; Virus; Oral lichen planus

\section{CORRESPONDING AUTHOR:}

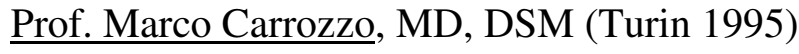

Professor of Oral Medicine

School of Dental Sciences

University of Newcastle upon Tyne

Framlington Place

Newcastle upon Tyne

NE2 4BW

E-mail:marco.carrozzo@ncl.ac.uk

Tel: 01912227818

This Study was presented as poster presentation in the $9^{\text {th }}$ Biennal Congress of the European Association of Oral Medicine. September 18-20, 2008 Salzburg, Austria 
OBJECTIVES: Oral Lichen Planus (OLP) is associated with hepatitis C virus (HCV) infection, and resembles graft-versus-host disease (GVHD) both clinically and histologically. The Killer Cell Immunoglobulin-like Receptor (KIR) genes encode a family of receptors expressed on NK and T cells and are supposed to play a significant role in GVHD and HCV infection. The aim of the present study was to analyze the association between OLP, HCV infection and variants in KIR gene expression.

METHODS: 81 patients with OLP (36 HCV+ve and $45 \mathrm{HCV}$-ve) and 217 healthy controls (HCVve) were typed for the presence of eight KIR genes and of HLA-Cw* alleles by polymerase chain reaction-sequence specific primer.

RESULTS: There were no significant differences in the frequency of the KIR genes and HLA$\mathrm{C} 1 / \mathrm{C} 2$ group alleles between cases and controls. We only found a significant difference in the frequency of the gene KIR2DL2 between HCV +ve and HCV-ve OLP patients.

CONCLUSIONS: The present data suggest that OLP is not associated with particular KIR genes or with $\mathrm{HLA}-\mathrm{CW}^{*}$ alleles in patients without $\mathrm{HCV}$ infection. Contrarily, the role of those genes in OLP-HCV+ve patients is unclear and might warrant further researches. 


\section{Introduction}

Lichen Planus (LP) is a relatively common chronic inflammatory disorder affecting stratified squamous epithelia often involving predominantly or exclusively the oral cavity (Eisen et al, 2005; Scully and Carrozzo, 2008). LP results probably from an abnormal T-cell-mediated immune response in which basal epithelial cells are recognized as foreign because of changes in the antigenicity of their cell surface. In most of the cases the cause of this immune-mediated basal cell damage is still unknown (Lodi et al, 2005). There appears to be a genetic predisposition in some patients, as evidenced by frequent association of cutaneous idiopathic LP with the HLA-DR1 (DRB1*0101) allele (Powell et al, 1986; La Nasa et al, 1995).

Oral LP (OLP) resembles graft-versus-host disease (GVHD) both clinically and histologically (Thomas et al, 1996, Sato et al, 2006). OLP can be associated with hepatitis C virus (HCV) infection and this association seems to be the case in many, albeit not all, regions of the world. (Carrozzo, 2008; Shengyuan et al, 2009; Bigby, 2009; Lodi et al, 2010). Moreover the HLA-DR6 allele is significantly expressed in Italian patients with OLP and HCV (Carrozzo et al, 2001). Natural killer (NK) cells represent a minor population of peripheral blood lymphocytes and major components of the innate immune system and are involved in both OLP and GVHD pathogenesis (Thomas et al, 1996; Parolini et al, 2007).

The function of NK cells in humans is regulated by a balance between opposite signals delivered by a set of HLA class I-specific inhibitory receptors and by a number of activating receptors and co receptors responsible for NK cell triggering (Lanier, 1998). By the combined use of these receptors, NK cells can discriminate between normal HLA class $\mathrm{I}^{+}$cells and cells that have lost the expression of HLA class I molecules as a consequence of tumor transformation or viral infection (Lanier, 2005).

The Killer cell immunoglobulin like receptor (KIR) genes encode a family of inhibitory and activating receptors expressed on NK cells and on a subset of T cells (Moretta and Moretta, 2004). These receptors are transmembrane glycoproteins that have two or three extracellular Ig-like domains for binding MHC class I ligands, a stem region, and a signalling domain (the transmembrane region and cytoplasmic tail) for transducing either an inhibitory or activating signal. The KIR locus, containing a family of polymorphic and highly homologous genes, maps to chromosome 19q13.4 within the 1Mb leukocyte receptor complex (LRC). KIRs are likely to play a significant role in the control of the immune response: indeed, through their interaction with KIR isotypes that inhibit natural killer cell activity, certain HLA class I molecules are now known to protect healthy cells from spontaneous destruction by NK-cell-mediated cytolysis. In particular, 
within the HLA class I complex, the HLA-Cw* genes encode most of the inhibitory KIR ligands. Binding with HLA-Cw antigens depend on the residue in position 80 and, on the basis of aminoacid at this position (asparagine-N- or lysine-K), these antigens are considered respectively belonging to C1 or C2 group (Moretta and Moretta, 2004; Carrington and Norman, 2003) (Table 1). However, on the basis of the presence or absence of the KIR genes 2DL1, 2DL2, 2DL3, it was possible to outline some different KIRhaplotypes: A, AB, B, C (Table 2).

The possible role of KIR genes in HCV infection (Khakoo et al, 2004) and in the onset of GVHD (Sun et al, 2005) has been reported in literature. Particularly, genes encoding the inhibitory NK cell receptor KIR2DL3 and its human leukocyte antigen C group 1 (HLA-C1) ligand directly influence resolution of HCV infection (Khakoo et al, 2004). On the other hand, mismatches of particular activating KIRs such that the patient was negative and the donor was positive (P-D+) resulted in increased risk of acute (KIR2DS1) and chronic (KIR2DS3) graft-versus-host disease (GVHD) (Giebel et al, 2009).

The aim of our study was to analyze the association between OLP, HCV infection and variants in KIR gene expression.

\section{Patients and methods}

\section{Patients}

In our study the patient group included 81 Italian patients (48 women and 33 men; median age 58 years, range 27-80 years) recruited between January 2000 and January 2001 at the Oral Medicine Section of the Department of Biomedical Science and Human Oncology of the University of Turin. Clinical diagnosis was always confirmed histologically. No patient was suspected to have drug- or restoration-related lichenoid lesions, and no patients presented histological signs of dysplasia.

Thirty-six consecutive patients had OLP with HCV infection (OLP-HCV+ve), whereas an age, sex and clinical comparable disease control group of 45 OLP patients did not have HCV infection (OLP-HCV-ve). Other causes of liver disease (such as autoimmune hepatitis, coinfection with other hepatotrophic viruses, drugs hepatotoxicity, etc.) were excluded, as described elsewhere (Carrozzo et al, 1996).

The control group included 217 unrelated healthy (HCV-ve) Italian individuals randomly selected from 22 immunogenetics laboratories located in northern, central and southern regions of Italy and already comprised in another study about KIR genes typing in Italian Caucasic population (Bontadini et al, 2006). 


\section{$\underline{\text { Virologic Assessments }}$}

The presence of serum anti-HCV antibodies (HCVAb) was determined by second or third generation ELISA (Enzyme-Linked Immunoabsorbent Assay, Ortho Diagnostic Systems, Raritan, NY, USA) and results confirmed with second or third generation RIBA (Recombinant Immunoblot Assay; Ortho Diagnostic and Chiron Corp, Emeryville, CA, USA). Moreover, HCV-RNA was detected by RT-PCR (Reverse Transcription Polymerase Chain Reaction; Amplicor, Roche Diagnostic Systems, Branchburg, NY, USA).

\section{KIR typing and HLA-C1/C2 group determination}

In order to analyse KIR/HLA-Cw* genes, DNA of our samples was previously extracted from peripheral blood samples drawn in EDTA (ethylenediaminetetraacetic acid) anticoagulant tubes using a micro salting-out procedure (Miller et al, 1988). The DNA concentration and the ratio were evaluated.

KIR typing and $\mathrm{C} 1 / \mathrm{C} 2$ group determination of HLA-Cw* alleles were performed by the PCR-SSP (Polymerase Chain Reaction-Sequence Specific Primers) method. Specific primer sequences for the KIR genes 2DL1, 2DL2, 2DL3, 2DL4, 2DS1, 2DS2, 3DL1 were deducted from the literature (Gomez-Lozano and Vilches, 2002), whereas for 3DL2 gene and HLA-Cw* alleles they were designed following the Genebank protocol to design primers for cDNA.

PCR products were transferred to the well of a $2 \%$ agarose gel. The DNA separation was performed at 280 Volts for 20 minutes. The amplification was checked on a UV transilluminator and photographed.

All 81 patients were typed for KIR genes and analyzed for HLA-C1/C2 group determination; as mentioned, all controls were previously typed for KIR genes within the Italian multicentre study, whereas we recruited only 46/217 controls, whose DNA was available or isolated de novo, for $\mathrm{C} 1 / \mathrm{C} 2$ group determination.

\section{$\underline{\text { Statistical analysis }}$}

Frequencies of KIR genes and HLA-C alleles were determined by direct counting. In this study we compared the frequency of the single KIR genes and HLA-C alleles between the cases and the 
control group and, within the cases, between the following different subgroups: $\mathrm{HCV}+\mathrm{ve} / \mathrm{HCV}$ ve; erosive OLP/non-erosive OLP; just oraloral/mucocutaneous LP as previously defined (Carrozzo et al, 2001). We also compared the frequency of the different KIR haplotypes (A, B, AB, and C) between the same groups. Differences in frequency between different groups were compared by the Chi-square test using the Statistical Package for Social Sciences (spss) software program (version 12, Chicago, IL, USA). Corresponding P-values were considered significant at values $<0.05$.

\section{Results}

$\underline{\text { Single KIR genes frequency }}$

There were no significant difference in the frequency of KIR genes between the OLP subjects and the healthy controls (Table 3). Similarly no significant difference was found comparing erosive OLP with non-erosive OLP (data not shown) or comparing exclusive oral LP patients with mucocutaneous LP patients (Table 3$)$. We only found a significant difference $(p=0.0326)$ in the frequency of KIR2DL2 and a trend towards significance in the frequency of 2DS2 $(p=0.0655)$ between HCV seronegative OLP and HCV seropositive OLP patients (Table 3).

\section{$\underline{\text { HLA-C alleles frequency }}$}

We did neither find any significant differences in the frequency of HLA-C1/C2 alleles between cases and controls nor between any of the subgroups compared (Table 4).

\section{$\underline{\text { KIR haplotypes frequency }}$}

There was neither significant difference in the frequency of KIR haplotypes between OLP patients and the controls nor in the subgroups (data not shown). 


\section{Discussion}

The aetiology of OLP has not been fully elucidated. Studies have suggested the presence of a genetic predisposition to the development of OLP (Scully et al, 1998). Most idiopathic cutaneous LP world-wide is in fact related to the HLA-DR1 (DRB1*0101 allele), whereas in Italy HCVrelated OLP appears to be particularly associated with the HLA class II allele HLA-DR6. Moreover a significant association was found between erosive OLP and HLA-DR3 allele (Carrozzo et al, 2001; Jontell et al, 1987).

NK cells are important components of the innate immune response (Williams et al, 2005). NK cells are regulated in part by inhibitory receptors that recognize MHC class I molecules on normal cells. In humans, inhibitory receptors that recognize classical MHC class I molecules belong to the KIR family. The reason for KIR diversity and the contribution of individual KIRs to signalling in NK cells and $\mathrm{T}$ cells are not fully understood, but their importance has been underscored by several recent genetic studies which have linked combinations of KIR and HLA genes with the outcome of various diseases (type I diabetes, psoriatic arthritis, HCV infection and others). Associations with different KIR-HLA combinations, involving activating KIR or inhibitory KIR genes to different extents, have been described. These data suggest that diseases can be modified by specific KIRligand interactions, rather than by global responsiveness of NK cells or T cells (Rajagopalan and Longo, 2005). In particular, many studies suggest the presence of an association between KIR genes (especially activating KIR genes) and diseases characterized by an alteration of the immune response like rheumatoid arthritis, scleroderma, lupus erythematosus, psoriasis, type I diabetes (Williams et al, 2005; Yen et al, 2006; van der Silk et al, 2003; Momot et al, 2004; Pellet et al, 2007). It is probable that activating KIR may synergize with TCR-mediated signals to cause aberrant immune activation and autoimmune reactions. Moreover, activating KIR would stimulate cytokine production by NK cells, which contributes to inflammation. (Rajagopalan and Longo, 2005).

A possible role of KIR genes in the pathogenesis of LP has not been investigated so far. However an association appears to be present between KIRs and GVHD (Sun et al, 2005) whose aspect is very similar to OLP, both clinically and histologically (Sato et al, 2006). Moreover KIR genes appear to be involved in the pathogenesis of diseases often associated with OLP, such as HCV infection and diabetes mellitus (Khakoo et al, 2004; van der Silk et al, 2003), and an altered activity of NK cells in LP patients has been suggested (Hunyadi et al, 1986). 
In our study we did not find any significant differences in the KIR genes frequency between OLP cases and healthy controls. We only found a significant difference in the frequency of the gene KIR2DL2 between HCV+ve and HCV-ve OLP patients. However this significant result is probably just due to the chronic HCV infection. In fact the low frequency of KIR2DL2 observed in HCV+ve OLP patients has been yet correlated with a persistent HCV infection (Montes-Cano et al, 2005).

These data may suggest that in the patients with OLP and HCV infection the virus persistence could exert a chronic immunological pressure which could contribute to the onset of the OLP lesions. However, this hypothesis is entirely speculative because in the present study no HCV+ve controls without OLP have been included.

Contrarily, the analysis of the HLA-Cw* genes has not pointed out any significant results, suggesting that the onset of OLP is not correlated with particular HLA-Cw* ligands.

In conclusion, the results of the present study suggest that KIR and HLA-Cw* genes are not involved in the pathogenesis of OLP without HCV infection whereas the role of those genes in OLP$\mathrm{HCV}+\mathrm{ve}$ patients is unclear and might warrant further researches.

\section{Acknowledgements}

This work has been supported by M.U.R.S.T. (ex quota 60\%) and the Department of Biomedical Sciences and Human Oncology, University of Turin

\section{Author Contributions}

M Carrozzo and A Amoroso have designed the study. A Elia, R Broccoletti and M Carrozzo collected the blood samples.V Mereu, E Dametto and ME Fasano made the laboratory investigations. S Rendine made the statistical analysis. A Elia and M Carrozzo wrote the paper. 


\section{References}

Bigby M. (2009) The relationship between lichen planus and hepatitis C clarified.Arch Dermatol 145:1048-50

Bontadini A, Testi M, Cuccia MC et al (2006). Distribution of killer cell immunoglobulin-like receptors genes in the Italian Caucasian population. J Transl Med 4: 44.

Carrington M, Norman P (2003). The KIR Gene Cluster. Bethesda (MD): National Library of Medicine (US), NCBI; Available from http://ncbi.nlm.nih.gov/entrez/query.fcgi?db=Books; 2003. Carrozzo M (2008). Oral diseases associated with hepatitis C virus infection. Part 2: lichen planus and other diseases. Oral Dis 14:217-28.

Carrozzo M, Gandolfo S, Carbone M et al (1996). Hepatitis C virus infection in Italian patients with oral lichen planus: a prospective case-control study. J Oral Pathol Med 25: 527-33.

Carrozzo M, Francia Di Celle P, Gandolfo S et al (2001). Increased frequency of HLA-DR6 allele in Italian patients with hepatitis C virus-associated Oral Lichen Planus. Br J Dermatol 144: 803-808. Eisen D, Carrozzo M, Bagan Sebastian J-V, Thongprasom K (2005). Oral lichen planus: clinical features and management. Oral Diseases 11: 338-349.

Giebel S, Nowak I, Dziaczkowska J et al (2009). Activating killer immunoglobulin-like receptor incompatibilities enhance graft-versus-host disease and affect survival after allogeneic hematopoietic stem cell transplantation. Eur J Haematol. 83:343-356.

Gomez- Lozano N, Vilches C (2002). KIR genotyping by polymerase chain reaction with sequencespecific primers: an update. Tissue Antigens 59: 184-193.

Hunyadi J, Simon M, Kornacher J, Hornstein OP (1986). Decreased Natural Killer Cell Activity in Lichen Ruber Planus. Acta Derm Venereol 66: 435-456.

Jontell M, Ståhlblad PA, Rosdahl I, Lindblam B (1987). HLA-DR3 antigens in erosive oral lichen planus, cutaneous lichen planus, and lichenoid reactions. Acta Odontol Scand 45: 309-12

Khakoo SI, Thio CL, Martin MP et al (2004). HLA and NK cell inhibitory receptor genes in resolving hepatitis $\mathrm{C}$ virus infection. Science 305: 872-874.

La Nasa G, Cottoni F, Mulargia M et al (1995). HLA antigen distributionin different clinical subgroups demonstrates genetic heterogeneity in lichen planus. Br J Dermatol 132: 897-900.

Lanier LL (1998). NK cell receptors. Anпu Rev Immunol 16: 359-93.

Lanier LL (2005). NK cell recognition. Annu Rev Immunol 23:225-74.

Lodi G, Pellicano R, Carrozzo M (2010). Hepatitis C virus infection and lichen planus: a systematic review with meta-analysis. Oral Dis Apr 19. [Epub ahead of print] 
Lodi G, Scully C, Carrozzo M et al (2005). Current controversies in oral lichen planus: report of an international consensus meeting. Part 1. Viral infections and etiopathogenesis. Oral Surg Oral Med Oral Pathol Oral Radiol Endod 100(1):40-51.

Miller SA, Dykers DD, Polesky HF (1988). A simple salting out procedure for extracting DNA from human nucleated cells. Nucleic Acid Research 16: 1215.

Momot T, Koch S, Hunzelmann N, et al (2004). Association of Killer cell immunoglobulin-like receptors with Scleroderma. Arthritis \& Rheumatism 50: 1561-1565.

Montes-Cano MA, Caro-Oleas JL, Romero-Gomez M et al (2005). HLA-C and KIR genes in hepatitis C virus infection. Hum Immunol 66(11): 1106-9.

Moretta L, Moretta A (2004). Killer immunoglobulin-like receptors. Current Opinion in Immunology 16: 626-633.

Parolini S, Santoro A, Marcenaro E et al (2007). The role of chemerin in the colocalization of NK and dendritic cell subsets into inflamed tissues. Blood 109:3625-32.

Pellet F, Siannis F et al (2007). KIRs and autoimmune disease: studies in systemic lupus erythematosus and scleroderma. Tissue Antigens 69: 106-108.

Powell FC, Rogers RS, Dickson ER, Moore SB (1986). An association between HLA-DR1 and lichen planus. Br J Dermatol 114: 473-478.

Rajagopalan S, Longo EO (2005). Understanding how combinations of HLA and KIR genes influence disease. JEM 201: 1025-29.

Sato M, Tokuda N, Fukumoto T et al (2006). Immunohistopathological study of the oral lichenoid lesions of chronic GVHD. J Oral Pathol Med 35: 33-6.

Scully C, Beyli M, Ferreiro MC et al (1998). Update on Oral Lichen Planus: Etiopathogenesis and Management. Crit Rev Oral Biol Med 9(1): 86-122.

Scully C, Carrozzo M (2008). Oral mucosal disease: Lichen planus. Br J Oral Maxillofac Surg 46:15-21.

Shengyuan L, Songpo Y, Wen W, Wenjing T, Haitao Z, Binyou W (2009). Hepatitis C virus and lichen planus: a reciprocal association determined by a meta-analysis. Arch Dermatol. 145(9):1040-1047.

Sun JY, Gaidulis L et al (2005). Killer Ig-like receptor (KIR) compatibility plays a role in the prevalence of acute GVHD in unrelated hematopoietic cell transplants for AML. Bone Marrow Transplantation 56: 525-530.

Thomas DW, Matthews JB, Prime SS (1996). Mucosal cell-mediated immunological changes associated with experimental graft-versus-host disease. J Oral Pathol Med 25(4):145-50. 
van der Silk AR, Koeleman BPC et al (2003). KIR in Type 1 Diabetes. Disparate distribution of activating and inhibitory natural killer cell receptors in patients versus HLA-matched control subjects. Diabetes 52: 2639-2642.

Williams AP, Bateman AR, Khakoo SI (2005). Hanging in the balance. KIR and their role in disease. Molecular Interventions 5: 226-240.

Yen JH, Lin $\mathrm{CH}$ et al (2006). Killer cell immunoglobulin-like receptor and rheumatoid arthritis. Scand J Rheumatol 35(2):124-7. 
Table 1- HLA-Cw alleles according to $\mathrm{C} 1$ and $\mathrm{C} 1$ grouping

\begin{tabular}{|l|l|}
\hline Group HLA & HLA- Cw Alleles \\
\hline C1 group * & $01,03,0411,0429,0611,07,08,12,14$, \\
& 1507,16 \\
\hline C2 group $* *$ & $0114,02,0307,0310,0315,0329,0345,04$, \\
& $05,06,0707,0709,0810,1204,1205,1209$, \\
& $1221,15,1602,1609,17,18$ \\
\hline
\end{tabular}

* Ligands to KIR: 2DL2, 2DL3, 2DS2

**Ligands to KIR: 2DL1, 2DS1 
Formatted: Left: 72 pt, Right: 72

pt, Width: 595.3 pt, Height: 841.9

pt, Header distance from edge: 35.4 pt, Footer distance from edge: 35.4

\begin{tabular}{|l|l|l|l|}
\hline Haplotypes & \multicolumn{4}{|c|}{ KIR Genes } \\
\hline & 2DL1 & 2DL2 & 2DL3 \\
\hline A & + & - & + \\
\hline B & - & + & - \\
\hline AB & + & + & + \\
\hline C & + & + & - \\
\hline C & - & + & + \\
\hline C & - & - & + \\
\hline C & - & - & - \\
\hline
\end{tabular}

Deleted: 1

Deleted: profiles

Deleted: Profiles 
Table 3. Difference in the frequency of KIR genes between the OLP group and Controls and in OLP subgroups

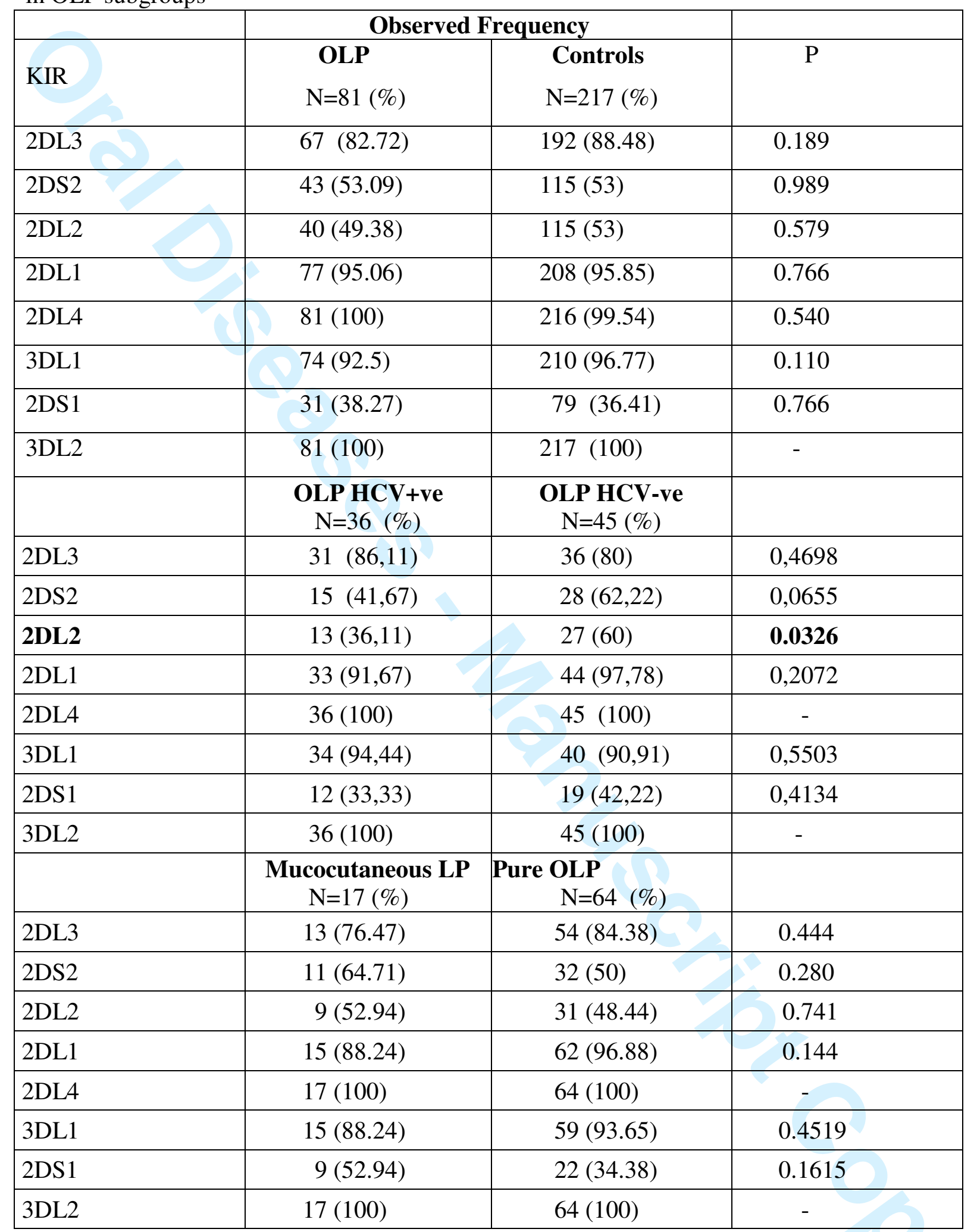


Table 4- Frequencies of HLA- C1/C2 antigens in cases and controls and in the subgroups analysed

\begin{tabular}{|c|c|c|c|}
\hline \multirow{2}{*}{ HLA-Cw } & \multicolumn{2}{|c|}{ Observed Frequency } & \multirow[b]{2}{*}{$\mathrm{P}$} \\
\hline & $\begin{array}{c}\text { OLP } \\
\mathrm{N}=81(\%)\end{array}$ & $\begin{array}{c}\text { Controls } \\
\mathrm{N}=46(\%)\end{array}$ & \\
\hline Group 1 & $30 \quad(37,04)$ & $16(34,78)$ & \multirow{3}{*}{0,3686} \\
\hline Group 2 & $10 \quad(12,35)$ & $10(21,74)$ & \\
\hline \multirow[t]{3}{*}{ Group $1 / 2$} & $41 \quad(50,62)$ & $20 \quad(43,48)$ & \\
\hline & 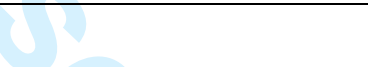 & & \\
\hline & $\begin{array}{c}\text { OLP HCV+ve } \\
\mathrm{N}=36(\%)\end{array}$ & $\begin{array}{c}\text { OLP HCV-ve } \\
\mathrm{N}=45(\%)\end{array}$ & \\
\hline Group 1 & $13(36.11)$ & $17(37.78)$ & \multirow{3}{*}{0.9301} \\
\hline Group 2 & $5(13.89)$ & $5(11.11)$ & \\
\hline \multirow[t]{2}{*}{ Group $1 / 2$} & $18(50)$ & $22(51.11)$ & \\
\hline & $\begin{array}{c}\text { Mucocutaneous LP } \\
\mathrm{N}=17(\%)\end{array}$ & $\begin{array}{c}\text { Pure OLP } \\
\mathrm{N}=64(\%)\end{array}$ & \\
\hline Group 1 & $6(35.29)$ & $24(37.5)$ & \multirow{3}{*}{0.7553} \\
\hline Group 2 & $3(17.95)$ & $7(10.94)$ & \\
\hline Group $1 / 2$ & $8(47.06)$ & $33(51.56)$ & \\
\hline
\end{tabular}

